Friday 1 June 2012

Plenary Session 4 - Changing the Game: Political Activism to Improve Health Care for Those with Advanced Illness - How the Coalition for Transformation of Advanced Care Aims to Reform the Care of Patients with Advanced Illness

\title{
48 THE NEED FOR ACTIVISM, BUILDING A COALITION FOR CHANGE, AND PUBLIC ENGAGEMENT
}

T Koutsoumpas ${ }^{1}$ Coalition to Transform Advance Care, USA

10.1136/bmjspcare-2012-000250.47

C-TAC is a large, active coalition of patient and consumer groups, care providers, private sector stakeholders, faith-based organizations, health care payers and others. Our vision is that all Americans with advanced illness, especially the sickest and most vulnerable, will receive comprehensive, high-quality care that is consistent with their goals and values and honors their dignity.

The C-TAC mission is to transform advanced illness care by empowering consumers, changing the health care delivery system, improving public and private policies, and enhancing provider capacity. We are assembling a diverse group of stakeholders to work together to:

- Identify, design and promote best-practice delivery models that ensure high-quality, coordinated care across all settings.

- Develop and disseminate innovative models of inter-professional advanced care education aimed at improving quality, shared decision making, and clinical care by cultivating respect, compassion and responsiveness in care delivery. 
- Develop and advocate for federal and state legislative, regulatory, judicial and administrative initiatives, as well as private policies, to improve care for those with advanced illness.

- Undertake a nationwide campaign of public education and engagement to help patients and their families make more informed decisions and to call for delivery system and policy change.

As Baby Boomers age, the number of people struggling with serious advanced illness will expand rapidly; we need action. Now is the time for stakeholders to take the initiative to develop and implement sustainable models of care delivery for the sickest and most vulnerable among us. 